\title{
Bat ticks revisited: Ixodes ariadnae sp. nov. and allopatric genotypes of $I$. vespertilionis in caves of Hungary
}

\author{
Sándor Hornok ${ }^{1 *}$, Jenő Kontschán ${ }^{2,3}$, Dávid Kováts ${ }^{4}$, Richárd Kovács ${ }^{5}$, Dorottya Angyal ${ }^{6}$, Tamás Görföl ${ }^{6,7}$, \\ Zsolt Polacsek ${ }^{8}$, Zsuzsa Kalmár ${ }^{9}$ and Andrei D Mihalca ${ }^{9}$
}

\begin{abstract}
Background: In Europe two ixodid bat tick species, Ixodes vespertilionis and I. simplex were hitherto known to occur. Methods: Bat ticks were collected from cave walls and bats in Hungary. Their morphology and genotypes were compared with microscopy and conventional PCR (followed by sequencing), respectively.

Results: A year-round activity of I. vespertilionis was observed. Molecular analysis of the cytochrome oxidase subunit I (COI) gene of twenty ticks from different caves showed that the occurrence of the most common genotype was associated with the caves close to each other. A few specimens of a morphologically different tick variant were also found and their COI analysis revealed only 86-88\% sequence homology with I. simplex and I. vespertilionis, respectively.
\end{abstract}

Conclusions: The microenvironment of caves (well separated from each other) appears to support the existence of allopatric I. vespertilionis COI genotypes, most likely related to the distance between caves and to bat migration over-bridging certain caves. The name I. ariadnae sp. nov. is given to the new tick species described here for the first time.

Keywords: Ixodes, Tick, Cave, Bat, Genotype

\section{Background}

In Europe, two ixodid bat tick species are known to occur [1]. The long-legged bat tick (Ixodes vespertilionis) has a broad host range and a worldwide distribution; accordingly, it was also reported from most of the European countries [2]. On the other hand, I. simplex is highly specialized to the bat Miniopterus schreibersii, and (although geographically widespread) it is usually found in low numbers during surveys [3]. This may be partly attributed to the difficulties in its diagnosis, which is not always clear [2]. The taxonomical relationship of the two bat tick species is also a matter of debate, as formerly they were classified as members of separate subgenera (Eschatocephalus and Pomerantzevella, respectively), which were later judged to be synonymous [4].

\footnotetext{
* Correspondence: hornok.sandor@aotk.szie.hu

${ }^{1}$ Department of Parasitology and Zoology, Faculty of Veterinary Science, Szent István University, Budapest, Hungary

Full list of author information is available at the end of the article
}

Furthermore, I. vespertilionis is usually collected from either bats [3] or cave walls [5], but I. simplex almost exclusively from bats $[2,3,6]$.

Concerning the epidemiological significance of bat ticks, I. vespertilionis was shown to be present outside caves (e.g. cellars or attics of houses, tree holes: [3]). This species may also infest humans [7] and may carry bartonellae [5]. However, I. simplex is unlikely to feed on humans, and its vector potential remains to be elucidated.

Recently, during collections of ticks in Hungarian caves [5] it was observed, that some specimens are morphologically different from both $I$. vespertilionis, and I. simplex. Arthur [2] also reported the existence of bat ticks, which show intermediate features between $I$. vespertilionis and I. simplex. Therefore, the primary aim of the present study was to collect large numbers of ticks from caves, in order to clarify their taxonomical status on both morphological and molecular bases. It was also within the scope of the survey to obtain data 
on the ecology of bat ticks, i.e. their seasonality and the distribution of cave-related (allopatric) genotypes.

The cytochrome oxidase subunit I (COI) gene was chosen for molecular analysis, on account of its suitability as a DNA-barcode sequence for animal/tick species identification [8,9]. The COI gene allows phylogenetic studies, because it is conserved enough within species, shows variability among species, and there are numerous sequences of this gene from ixodid ticks already deposited in the GenBank.

\section{Methods}

Tick collections of the present study were carried out in 2012-2013, and consisted of three parts. The main collection site included three caves (Legény Cave, Leány Cave and Ariadne Cave; entrances within $1 \mathrm{~km}$; central coordinate: $47^{\circ} 41^{\prime} 57.67^{\prime \prime} \mathrm{N}, 18^{\circ} 50^{\prime} 39.24^{\prime \prime} \mathrm{E}$ ) in the Pilis Mountains, that were visited repeatedly during the winter, spring and autumn months. A few ticks were also provided by speleologists from more distant locations selected randomly (i.e. seven caves in the Gerecse, Bükk and Mecsek Mountains: Figure 1).

Additionally, five ticks (three nymphs, one larva with unusual morphology; and one I. simplex nymph from Miniopterus schreibersii: Figure 1) removed from five bats during their mating period (August-September) were included in the present study. These animals were caught (as part of a monitoring program) at the entrance of caves between sunset and dawn, using standard Ecotone mist-nets (Gdynia, Poland) with $12 \mathrm{~m}$ length,
$2.5 \mathrm{~m}$ height and $14 \times 14 \mathrm{~mm}$ mesh $[10,11]$. Ticks were immediately put into and stored in $70 \%$ ethanol.

DNA extraction from ticks was carried out as described [12]. For barcoding a portion of the COI gene was amplified from these tick DNA samples with the universal primer pair $\mathrm{LCO} / \mathrm{HCO}$ [13] in a concentration of $10 \mathrm{pmol} / \mu \mathrm{l}$. PCR conditions were the following: $94^{\circ} \mathrm{C}$, $5 \mathrm{~min}$; then 35 cycles of $94^{\circ} \mathrm{C}, 40 \mathrm{sec}, 44^{\circ} \mathrm{C}, 40 \mathrm{sec}$ and $72^{\circ} \mathrm{C}, 1 \mathrm{~min}$; and final extension at $72^{\circ} \mathrm{C}$ for $5 \mathrm{~min}$. The length of PCR product was approximately $700 \mathrm{bps}$. After electrophoresis in $1.5 \%$ gel the bands were excised and purified by using the Wizard ${ }^{\circ} \mathrm{SV}$ Gel and PCR CleanUp System (Promega, USA). Sequencing was done by Macrogen Inc. (Korea). Sequences were submitted to the GenBank (accession numbers KJ490305 for I. simplex, and KJ490307-KJ490311 for genotypes of I. vespertilionis designated A-E, respectively). Phylogenetic analysis was performed with Mega 5.2 program package, and the tree was constructed by Neighbor-Joining test.

Scanning micrographs were made in the Hungarian Natural History Museum (Budapest) with a HITACHI SN 2600 scanning electron microscope. All investigated specimens were sputter coated by golden-palladium.

\section{Ethical approval}

Authorization for bat capture was provided by the National Inspectorate for Environment, Nature and Water (No. 14/ 2138-7/2011). Bat banding licence numbers are TMF-14/ $32 / 2010$ and TMF-493/3/2005.

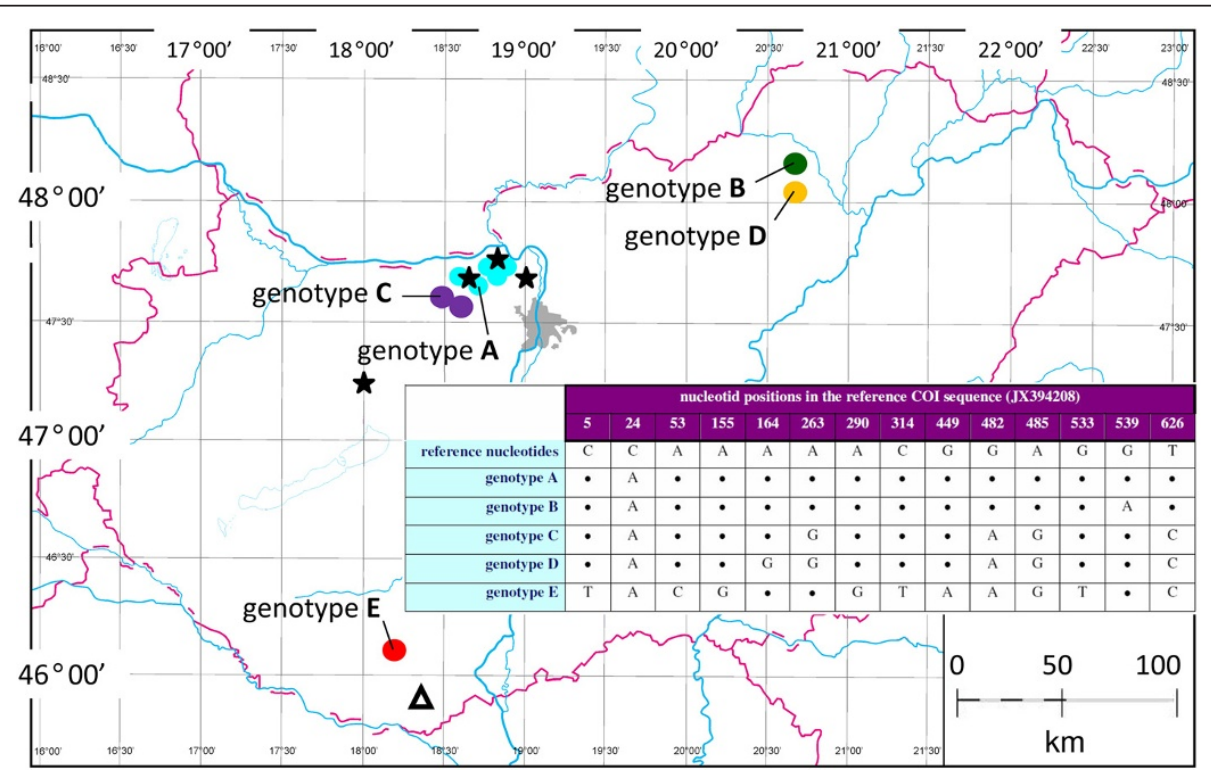

Figure 1 Map of Hungary showing the geographical distribution of cave-related, allopatric $I$. vespertilionis genotypes (coloured dots), and collection sites of $I$. ariadnae sp. nov. (stars). I. simplex was removed from Miniopterus schreibersii in southern Hungary (triangle). The table insert illustrates nucleotide differences between the genotypes according to a reference sequence with the highest similarity to the Hungarian isolates. 


\section{Results}

\section{Spatiotemporal distribution of $I$. vespertilionis}

In the caves, altogether 535 ticks were collected: 527 I. vespertilionis (220 males, 119 females, 171 nymphs and 17 larvae), and eight specimens showing different morphology (only engorged females). Concerning I. vespertilionis, except for the summer months (with low tick activity) nonparasitic males outnumbered females in the populations. The presence of questing females on cave walls appeared to be equilibrated between the seasons (Table 1). However, the proportion of nymphs was more pronounced during the spring and autumn. Larvae were observed from March to June.

Twenty ticks were selected for molecular analysis, including 15 specimens of $I$. vespertilionis (eight from the main collection sites, seven from other caves), four specimens with different morphology, and for comparison one $I$. simplex collected from Miniopterus schreibersii. In the three caves of the main collection site only genotype A was identified (corresponding to 8 tick specimens). This genotype was also found in two caves within $20 \mathrm{~km}$ westward, but not in any other, more distant caves. In two further caves within $40 \mathrm{~km}$ southwest genotype $\mathrm{C}$ was identified, and in three caves approx. $200 \mathrm{~km}$ to the east and to the south three other genotypes (B, D, and E: Figure 1). Genotypes A, B, C, D and $E$ differed from the reference sequence (accession number JX394208) in one, two, five, six or eleven nucleotides, respectively (Figure 1). Their phylogenetic relationships with each other and further ixodid species occurring in Europe are shown on Figure 2.

\section{Description of Ixodes ariadnae Hornok sp. nov. Taxonomic summary}

Phylum Arthropoda, class Arachnida, subclass Acari, family Ixodidae, genus Ixodes.

\section{Diagnosis}

Medium size (engorged females 6-7 $\mathrm{mm}$ ) prostriate ticks. The legs long, palps short and hypostome medium length. Scutum rounded, broad hexagonal, posteriorly curved, with deep cervical grooves on engorged specimens. Hair covering sparse both dorsally and ventrally. Only engorged females, nymphs and a larva were collected. Male is unknown.

\section{Type material and locality}

Holotype (1) female, from Leány Cave, Pilis Mountains, Hungary, (collected by D. Angyal, March 31, 2012).

Paratypes (2) nymph, from Myotis alcathoe, Pisznice Cave, Gerecse Mountains, Hungary (collected by D. Kováts, August 25, 2012); (3)-(6) three females from Leány Cave and one female from Legény Cave, Pilis Mountains,
Hungary, (collected by D. Angyal, March 31, 2012); (7)-(9) three females from Leány Cave, Pilis Mountains, Hungary, (collected by S. Hornok, March 24, 2013); (10) nymph from Plecotus auritus at Szopláki-ördöglyuk Cave, Pilis Mountains, Hungary, (collected by D. Kováts, April 6, 2012); (11) nymph from Myotis blythii at Szopláki-ördöglyuk Cave, Pilis Mountains, Hungary, (collected by D. Kováts, September 4, 2012); (12) larva from Myotis alcathoe at Alsópere, Bakony Mountains, Hungary, (collected by D. Kováts, July 27, 2013).

Holotype and paratypes (2), (4)-(6) are stored in alcohol and deposited at the Department of Parasitology and Zoology, Szent István University. Paratypes (8)-(10) are stored in alcohol and deposited in Soil Zoology Collection of the Hungarian Natural History Museum. Paratypes (3), (7), (11) and (12) were used for molecular phylogenetical comparison.

\section{Morphology}

Anal groove anterior to the anus (genus Ixodes).

Female (engorged): Length $6 \mathrm{~mm}$. Legs long (tarsus I: $1.5 \mathrm{~mm}$ ). Haller's organ open, long, confluent, with 11 setae in three groups. On the basis capituli posterolaterally blunt flange, posterior edge with dorsal ridge (maximum width $0.5 \mathrm{~mm})$. Palps short $(0.44 \mathrm{~mm})$, broad at the distinct joining of segments II-III. Hypostome of medium length $(0.35 \mathrm{~mm})$, with 10 rows of broad teeth, situated ventrally in four lines. Scutum rounded, broad hexagonal, with a shape index of 1.2. Idiosoma has sparse hair covering both dorsally and ventrally. Coxae are convex posteroexternally, with rounded surface. Genital pore between coxae III. Anal groove posteriorly divergent. Spiracle openings oval, with irregular outline.

Nymph (engorged): Length $3 \mathrm{~mm}$. Legs moderately long (tarsus I: $0.75 \mathrm{~mm}$ ). Basis capituli at maximum width $0.35 \mathrm{~mm}$. Palps short $(0.2 \mathrm{~mm}$; segments II + III: $0.125+0.075 \mathrm{~mm})$, broad at the distinct joining of segments II-III. Hypostome of medium length $(0.13 \mathrm{~mm})$. Scutum rounded, broad hexagonal (length: $0.72 \mathrm{~mm}$, width: $0.6 \mathrm{~mm}$, shape index 1.2). Idiosoma has sparse hair covering both dorsally and ventrally. Spiracles oval, with irregular outline.

\section{Differential diagnosis}

Characteristics of engorged females in comparison with I. vespertilionis and I. simplex are shown in Table 2, Figures 3, 4, 5, 6.

\section{Gene sequences}

Mitochondrial cytochrome oxidase subunit I (COI) gene sequence deposited in the GenBank is KJ490306. Its phylogenetic relationships are shown on Figure 2. 
Table 1 Collection data of $I$. vespertilionis in caves according to seasons

\begin{tabular}{|c|c|c|c|c|c|c|c|c|c|c|c|c|c|c|c|c|}
\hline & \multicolumn{4}{|c|}{ Winter (6/6) } & \multicolumn{4}{|c|}{ Spring (18/12) } & \multicolumn{4}{|c|}{ Summer (3/3) } & \multicolumn{4}{|c|}{ Autumn (4/4) } \\
\hline & Larvae & Nymphs & Males & Females & Larvae & Nymphs & Males & Females & Larvae & Nymphs & Males & Females & Larvae & Nymphs & Males & Females \\
\hline Total number & - & 5 & 23 & 7 & 16 & 114 & 160 & 92 & 1 & - & 3 & 3 & - & 52 & 34 & 17 \\
\hline Percentage & - & $14 \%$ & $66 \%$ & $20 \%$ & $4 \%$ & $30 \%$ & $42 \%$ & $24 \%$ & $14 \%$ & - & $43 \%$ & $43 \%$ & - & $50 \%$ & $33 \%$ & $17 \%$ \\
\hline Presence of bats & \multicolumn{4}{|c|}{ +++ } & \multicolumn{4}{|c|}{++} & \multicolumn{4}{|c|}{+} & \multicolumn{4}{|c|}{++} \\
\hline
\end{tabular}

Next to each season the number of visists per number of caves is shown in brackets. 


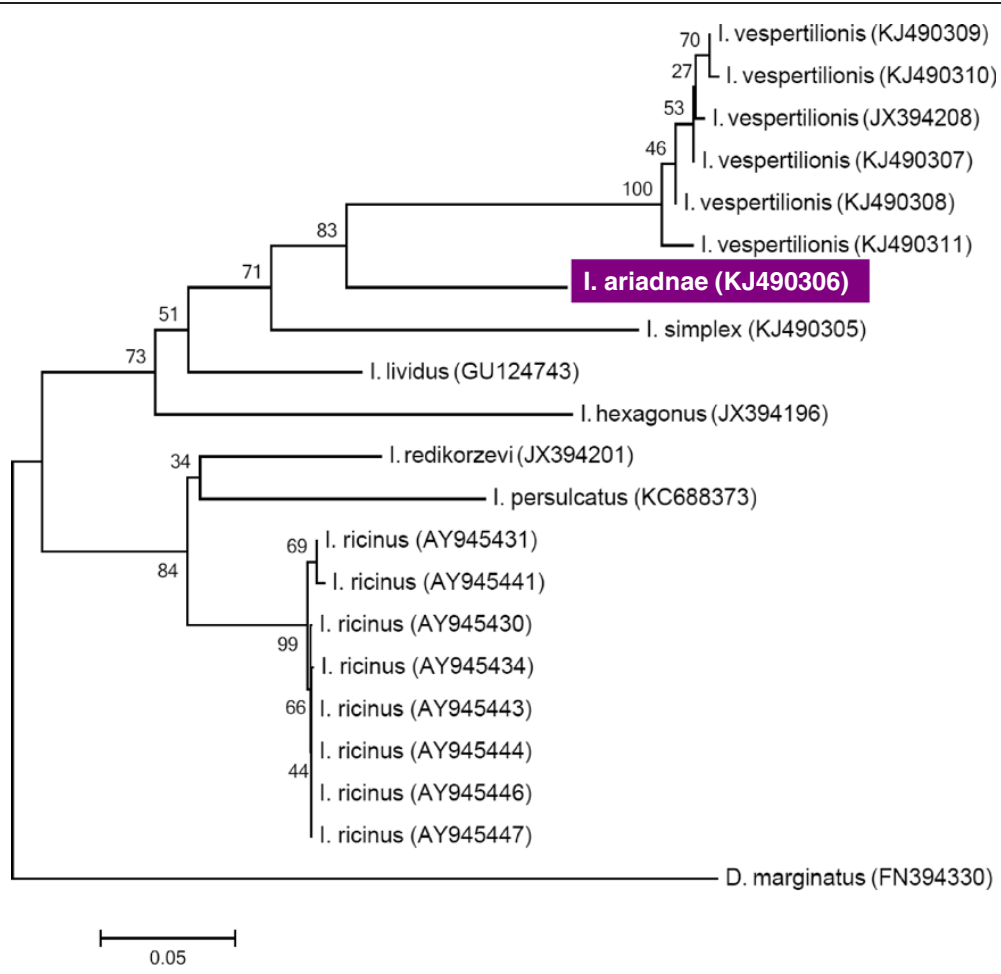

Figure 2 Phylogenetic relationship of $I$. ariadnae sp. nov., $I$. vespertilionis genotypes and $I$. simplex inferred from COI gene analysis in the present study, in comparison with other Ixodes spp. and Dermacentor marginatus based on sequences deposited in the GenBank.

Table 2 Morphological comparison of I. vespertilionis, I. ariadnae sp. nov. and I. simplex female

\begin{tabular}{|c|c|c|c|}
\hline Trait & I. vespertilionis* & I. ariadnae sp. nov. & I. simplex* \\
\hline Max. engorged size & 10 & 7 & 4.5 \\
\hline Length of legs & long (tarsus I: 1.6) & long (tarsus I: 1.5) & moderately long (tarsus I: 0.73) \\
\hline \multirow[t]{2}{*}{ Basis capituli } & - dorsally posterolaterally flange & - dorsally posterolaterally flange & $\begin{array}{l}\text { - dorsally no flange (ventrolaterally } \\
\text { triangular ridge) }\end{array}$ \\
\hline & - posteriorly straight & $\begin{array}{l}\text { - posteriorly slightly curved with dorsal } \\
\text { ridge }\end{array}$ & - posteriorly sinuous \\
\hline $\begin{array}{l}\text { Palps (II+III } \\
\text { segments) }\end{array}$ & long, narrow $(0.39+0.22)$ & short, broad $(0.28+0.16)$ & short $(0.16+0.14)$ \\
\hline $\begin{array}{l}\text { Joining of II-III } \\
\text { segments }\end{array}$ & distinct & distinct & indistinct \\
\hline Hypostome & $\begin{array}{l}\text { long, } 15 \text { rows of slender teeth, ventrally } \\
\text { in 6-8 lines }\end{array}$ & $\begin{array}{l}\text { medium, } 10 \text { rows of broad teeth, } \\
\text { ventrally in } 4 \text { lines }\end{array}$ & $\begin{array}{l}\text { short, } 8 \text { rows of broad teeth, ventrally in } \\
4-6 \text { lines }\end{array}$ \\
\hline Areae porosae & large, oval, interval broad & large, oval, interval slightly broad & large, oval, interval narrow \\
\hline Scutal setae & anterolaterally prominent & anterolaterally very few & anterolaterally prominent \\
\hline $\begin{array}{l}\text { Scutal length per } \\
\text { width }\end{array}$ & 1.76/1.08 (approx. 1.6) & 1.15/0.95 (approx. 1.2) & 1.13/0.8 (approx. 1.4) \\
\hline $\begin{array}{l}\text { Idiosoma hair } \\
\text { covering }\end{array}$ & dense & sparse & dense \\
\hline Coxae & posteroexternally concave, surface flat & $\begin{array}{l}\text { posteroexternally convex, surface } \\
\text { rounded }\end{array}$ & posteroexternally concave \\
\hline Anal groove & parallel & posteriorly slightly divergent & posteriorly markedly divergent \\
\hline Spiracle opening & oval, regular outline & oval, irregular outline & (sub)circular, broad \\
\hline
\end{tabular}

*Descriptions according to Arthur (1956), Babos and Janisch (1958), Nosek and Sixl (1972).

Sizes are given in $\mathrm{mm}$. 


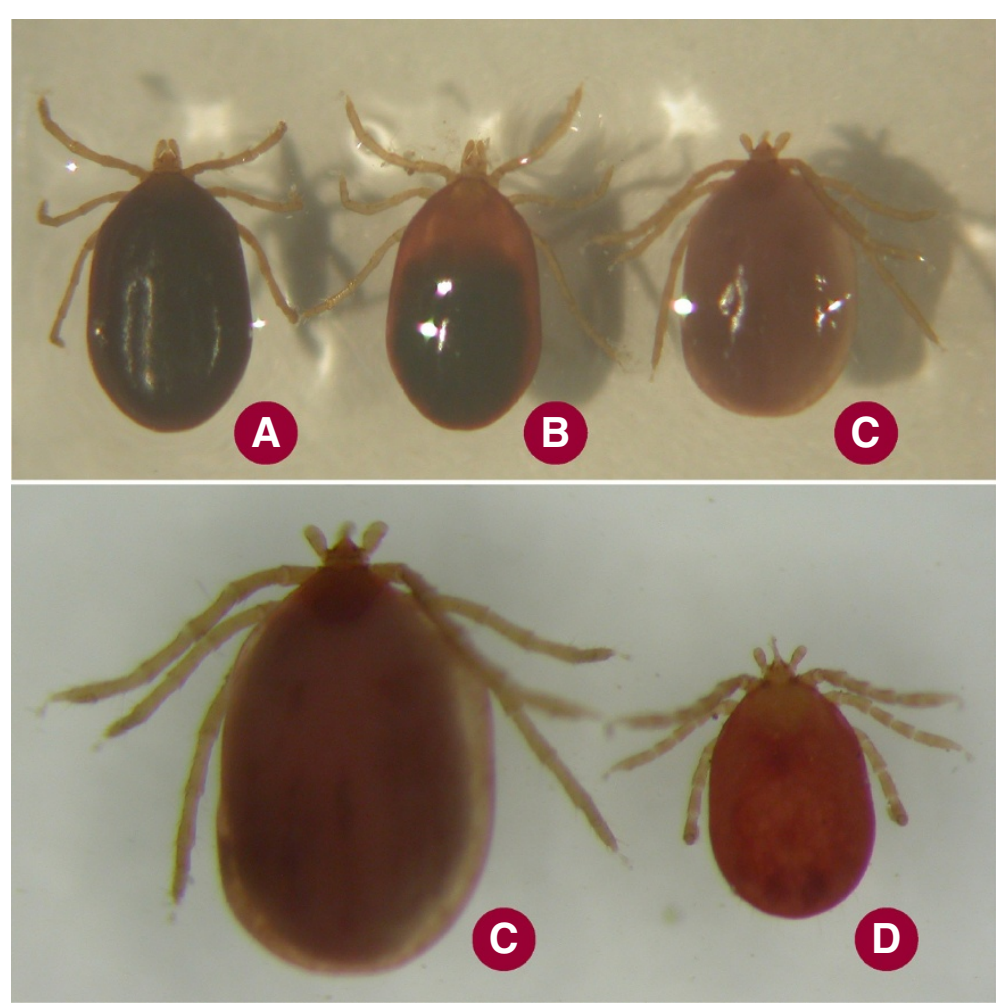

Figure 3 Larva of $I$. ariadnae sp. nov. collected from Myotis alcathoe and showing apolysis (C), in comparison with $I$. vespertilionis larvae from the cave wall without (A) or with apolysis (B); and (D) I. simplex larva collected from Miniopterus schreibersii.

\section{Host records and distribution}

Myotis alcathoe (of two specimens), Myotis blythii and Plecotus auritus. Distribution is shown on Figure 1.

\section{Etymology}

The name of the new species refers to Ariadne, the Greek mythological heroine associated with labyrinths.
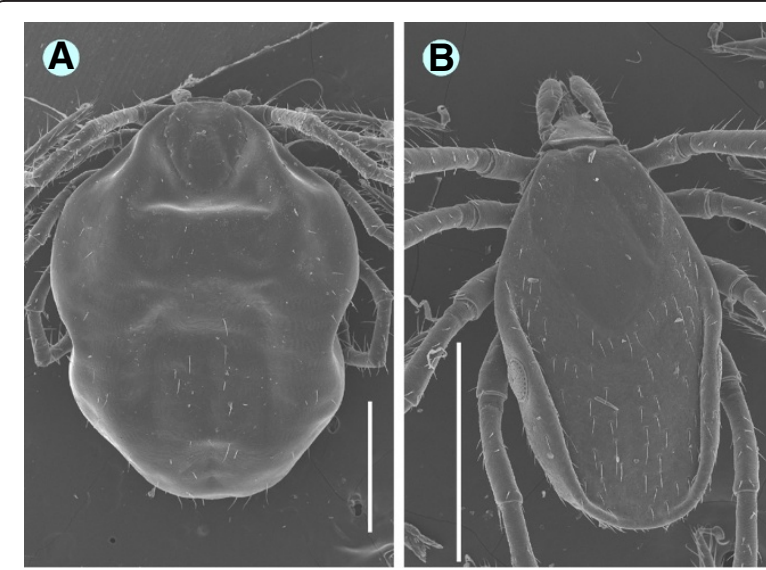

Figure 4 Scanning electron microscopy (SEM) pictures of engorged $I$. ariadnae sp. nov. nymph (A) and unfed $I$. vespertilionis nymph (B) (bars: $1 \mathrm{~mm})$.
Its relevance to the new species is that most specimens were collected at the caves in the Ariadne Cave system.

\section{General}

In accordance with section 8.5 of the ICZN's International Code of Zoological Nomenclature, details of the new species have been submitted to ZooBank with the life science identifier (LSID) zoobank.org:pub: F9432D03-627D-4D86A307-D9A8E8300361.

\section{Discussion}

Current knowledge on the taxonomy and ecology of Ixodes ticks of bats is vague. The review by Arthur [2] notes that descriptions are inadequate in many respects. Data on the seasonal activity of the most widespread species, $I$. vespertilionis have become available only recently $[3,14]$, and these are restricted to ticks collected from bats. At the same time, with growing concern about using molecular methods for the analysis of the taxonomical status of ticks, these were not applied to compare bat ticks, despite the long-known uncertainty in the morphology [2] and nomenclature $[15,16]$ of relevant species. The present study was undertaken to compensate for this lack of information and to contribute to the taxonomy and ecology of ticks that are specialized to 

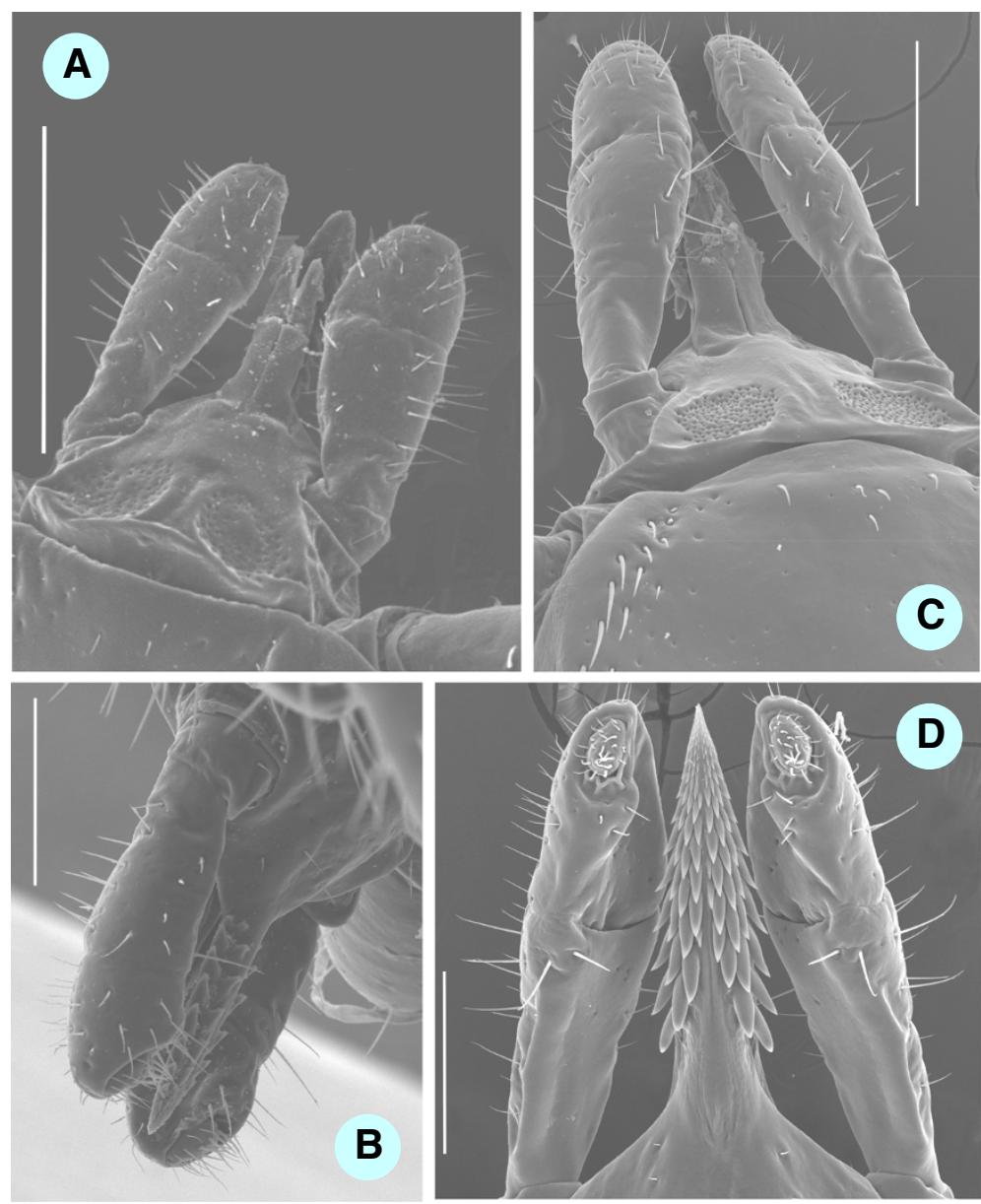

Figure 5 SEM pictures of head parts of female ticks: engorged I. ariadnae sp. nov. (A - dorsal, bar $=500 \mu \mathrm{m} ; \mathrm{B}$ - ventral, bar $=250 \mu \mathrm{m}$ ) and unfed $I$. vespertilionis ( - dorsal, bar $=250 \mu \mathrm{m} ; \mathrm{D}$ - ventral, bar $=250 \mu \mathrm{m}$ ).

bat hosts and have off-host stages living underground, in caves.

Concerning the seasonality of $I$. vespertilionis in caves, tick numbers (including all stages) appeared to be highest in the spring time, in line with what was reported on ticks collected from bats $[3,14]$. In the present study immature stages were found in all seasons, and this may indicate a continuous, year-round activity in the protected, underground shelters (meaning less exposure to weather variables), with increase or decrease in tick numbers depending on the presence of hosts. Similarly, the blood-sucking of I. simplex larvae and nymphs on bats was observed throughout the year, with some seasonal differences [6]. The low number of ticks during the summer time in this study can be explained by hiding ("over-summering") of stages in the absence of bat hosts in many of the caves, as some bat colonies use different roosts during the winter (i.e. their hibernation) and summer (June: nursing, August-September: mating). Arthur [2] also noted that during the summer time only a few males were reported in caves by some authors. On the other hand, female ticks were not observed on bats during the summer and autumn in another survey [14], but in this study were shown to be present in caves. These females may have developed from nymphs that completed their blood meal in the previous season.

A significant part of the life cycle of ixodid ticks is spent off-host, and in case of Ixodes spp. even mating can take place in the environment. Unlike overlapping populations of most ixodid ticks that live on large, continuous land surface biotopes, the small populations and habitats of $I$. vespertilionis in caves are physically well separated, only connected by bat migration. However, because the majority of bats prefer to use the same caves for hibernation repeatedly [17], this may constitute further restrictions for genetic exchange between $I$. vespertilionis populations. Correspondingly, this physical and "host behavioural" separation may entail a high degree of reproductive isolation, a prerequisite for the formation and establishment of divergent genotypes (in the long run speciation).

The present data show that divergent COI genotypes of $I$. vespertilionis exist. Only genotype A and $\mathrm{C}$ were 

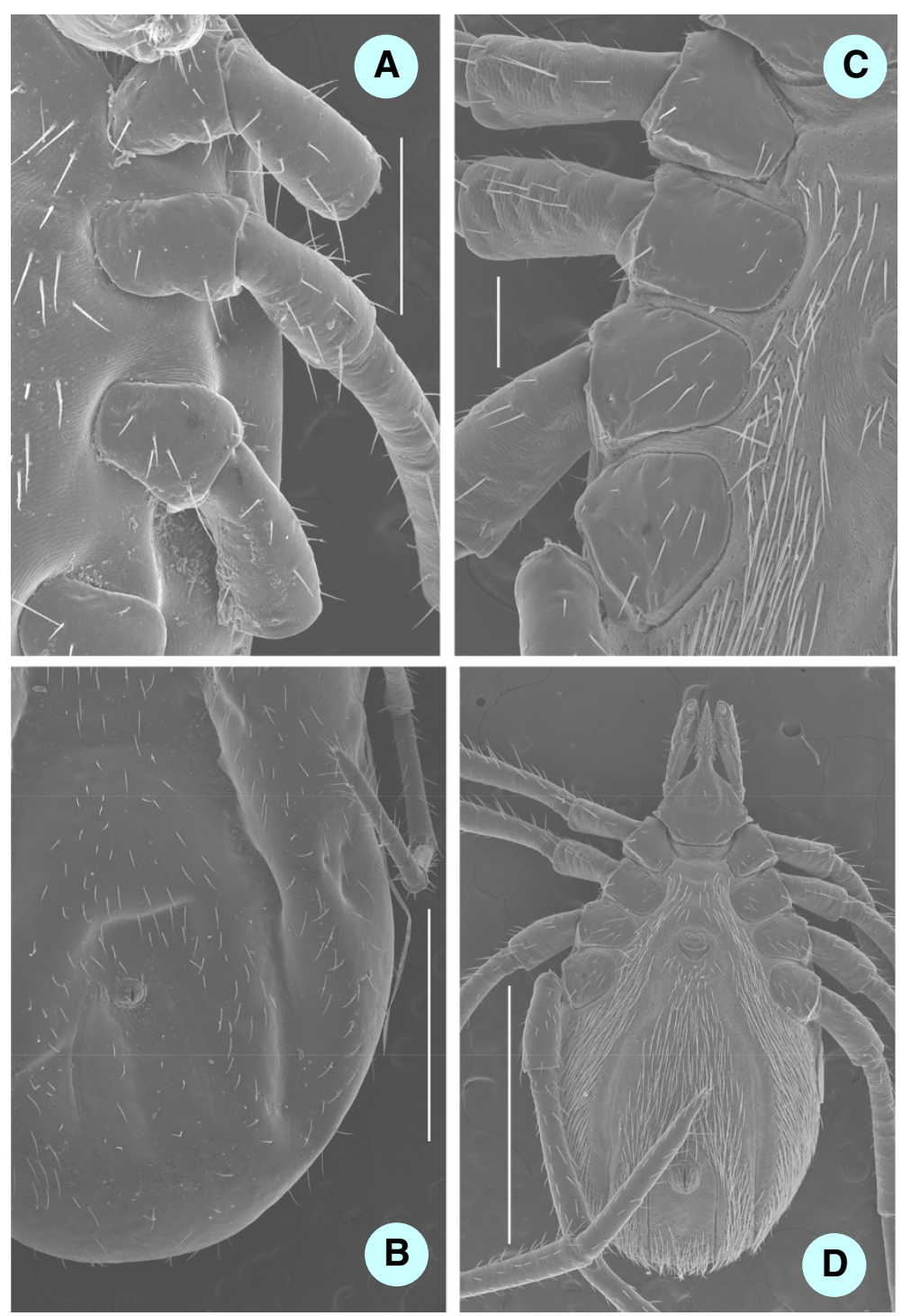

Figure 6 SEM pictures of ventral parts of female ticks: engorged I. ariadnae sp. nov. (A - coxae, bar $=500 \mu \mathrm{m}$; B - sparse hair covering, bar $=2 \mathrm{~mm}$ ) and unfed $I$. vespertilionis ( $C$ - coxae, bar $=250 \mu \mathrm{m} ; D$ - dense hair covering, bar $=2 \mathrm{~mm}$ ).

identified repeatedly, and only in caves nearby. As genotype A ticks collected at the main collection site were not found in distant caves (which had further, different genotypes), these preliminary results suggest that the occurrence of $I$. vespertilionis genotypes may be associated with particular cave(s). On the contrary, I. ricinus isolates of different origin did not show correlation of genotype and geographical location [18]. As concluded from bat ringing data, the three caves of the main collection site and the two westward (where genotype A was found) are connected by bat migration [10,11], thus making the transport of $I$. vespertilionis possible. Bat recaptures in other countries also reflected, that a small interchange of bats between caves close to each other does occur [17]. On the other hand, large distance, mountain ranges or other limiting factors of bat migration may prevent contact (genetic exchange of ticks via bats) between more distant caves.

However, the COI sequences of all four analysed specimens of $I$. ariadnae sp. nov. were identical, although one was collected at a more distant location (Figure 1), reflecting that this tick species has different bat hosts (with different migration habits) from those of I. vespertilionis. Hosts of the latter species are mainly Rhinolophus species [3], whereas in the present study I. ariadnae sp. nov. was collected from three species of other bat genera. At the same time Miniopterus schreibersii (the specific host of $I$. simplex) is an unlikely host for I. ariadnae sp. nov., because this bat species does not occur in any of the caves where engorged female ticks were collected. 
The COI sequence of $I$. ariadnae sp. nov. had only $88 \%$ and $86 \%$ similarities with I. vespertilionis and I. simplex, respectively (which showed $85 \%$ COI sequence homology with each other). The similarities of COI sequences between tick species of the same genera were estimated to range from $70 \%$ to $94 \%$ [19]. Accordingly, in comparison with the two hitherto described bat tick species in Europe, the $86-88 \%$ sequence similarity of $I$. ariadnae sp. nov. supports its taxonomical status as a separate species. Phylogenetically this species is closer to I. vespertilionis, but is placed in a separate cluster, supported by high bootstrap value (Figure 2). Confirming this, its morphology and hosts have also been shown to be different from both $I$. vespertilionis and I. simplex.

Further molecular taxonomical studies will be undertaken to investigate the ecology and host associations of this novel species in a broader context.

\section{Conclusion}

I. vespertilionis shows year-round activity in caves of Hungary, but larger populations during the autumn, winter and spring and "over-summering" in low numbers. The microenvironment of caves (well separated from each other) appears to support the existence of allopatric genotypes, most likely related to the distance between caves and to bat migration over-bridging certain caves. During the present study a morphologically and genetically distinct new bat tick species was found and is described for the first time. The name I. ariadnae sp. nov. is given to this species.

\section{Competing interests}

No competing interests exist.

\section{Authors' contributions}

SH initiated and supervised the study, processed the samples, extracted the DNA and wrote the manuscript. JK made the electron microscopic pictures and performed phylogenetic analysis. DK, RK, DA, TG and ZSP significantly contributed to the sample collection. ZSK performed molecular analysis and ADM arranged, designed and supervised the Romanian part of the study. All authors read and approved the manuscript.

\section{Acknowledgements}

The survey was organized in the framework of the EurNegVec COST Action TD1303. For AD Mihalca the research was funded from grant IDEI PCE 236/2011.

\footnotetext{
Author details

'Department of Parasitology and Zoology, Faculty of Veterinary Science, Szent István University, Budapest, Hungary. ${ }^{2}$ Plant Protection Institute, Centre for Agricultural Research, Hungarian Academy of Sciences, Budapest, Hungary. ${ }^{3}$ Department of Zoology and Animal Ecology, Szent István University, Gödöllő, Hungary. ${ }^{4}$ Department of Evolutionary Zoology and Human Biology, University of Debrecen, Debrecen, Hungary. ${ }^{5}$ Ariadne Caving Group, Pilis, Hungary. ${ }^{6}$ Department of Zoology, Hungarian Natural History Museum, Budapest, Hungary. 'Institute for Veterinary Medical Research, Centre for Agricultural Research, Hungarian Academy of Sciences, Budapest, Hungary. ${ }^{8}$ Hungarian Karst- and Cave Research Society, Budapest, Hungary. ${ }^{9}$ Department of Parasitology and Parasitic Diseases, Faculty of Veterinary Medicine, University of Agricultural Sciences and Veterinary Medicine, Cluj-Napoca, Romania.
}

Received: 10 March 2014 Accepted: 23 April 2014

Published: 27 April 2014

\section{References}

1. Nosek J, Sixl W: Central-European Ticks (Ixodoidea). Key for determination. Jahrbuch der naturwissenschaftlichen Abteilung Joanneum 1972, 1/2:61-92

2. Arthur DR: The Ixodes ticks of Chiroptera (Ixodoidea, Ixodidae). J Parasitol 1956, 42:180-196.

3. Sevcik M, Kristofik J, Uhrin M, Benda P: New records of ticks (Acari: Ixodidae) parasitising on bats in Slovakia. Vespertilio 2010, 13/14:139-147.

4. Clifford CM, Keirans JE, Kohls GM: Systematics of the subfamily Ixodinae (Acarina: Ixodidae). 1. The subgenera of Ixodes. Ann Entomol Soc Am 1973, 66:489-500.

5. Hornok S, Kovács R, Meli ML, Kontschán J, Gönczi E, Gyuranecz M, Dán Á, Molnár $V$, Hofmann-Lehmann R: First detection of bartonellae in a broad range of bat ectoparasites. Vet Microbiol 2012, 159:541-543.

6. Lourenco S: Ecology of a host-parasite system. A study in temperate cavedwelling bats. Portugal: PhD Thesis, University of Lisboa; 2008.

7. Piksa K, Nowak-Chmura M, Siuda K: First case of human infestation by the tick Ixodes vespertilionis (Acari: Ixodidae). Int J Acarol 2013, 38:1-2.

8. Hebert PD, Ratnasingham S, de Waard JR: Barcoding animal life: cytochrome coxidase subunit 1 divergences among closely related species. Proc Biol Sci 2003, 270(Suppl 1):S96-S99.

9. Lv J, Wu S, Zhang Y, Chen Y, Feng C, Yuan X, Jia G, Deng J, Wang C, Wang Q, Mei L, Lin X: Assessment of four DNA fragments (COI, 16S rDNA, ITS2, $12 \mathrm{~S}$ rDNA) for species identification of the Ixodida (Acari: Ixodida). Parasit Vectors 2014, 7:93.

10. Kováts D, Kurali A, Wizl V, Kukoda O, Surányi D, Penszka K, Urbányi B: First results of the bat research programme in the Danube band. In Proceedings of the 7th Biological Symposium of the Carpathian Basin (October 13-14, 2011, Budapest). Edited by Gyenis G; 2011:123-126.

11. Kováts D, Csanádi D, Kukoda O, Kurali A, Ujhegyi N: Nursing colonies of the mouse-eared bat (Myotis myotis Borkhausen, 1797) and the lesser mouse-eared bat (M. blythii Tomes, 1857) in underground roosts of the Gerecse and the Visegrádi Mts. Miskolc: International Conference of cave-dwelling bats; SPELEOBATS Hungary; 2012.

12. Hornok S, Kováts D, Csörgő T, Meli ML, Gönczi E, Hadnagy Z, Takács N, Farkas R, Hofmann-Lehmann R: Birds as potential reservoirs of tick-borne pathogens: first evidence of bacteraemia with Rickettsia helvetica. Parasit Vectors 2014, 7:128.

13. Folmer O, Black M, Hoeh W, Lutz R, Vrijenhoek R: DNA primers for amplification of mitochondrial cytochrome $C$ oxidase subunit I from diverse metazoan invertebrates. Mel Marine Biol Biot 1994, 3:294-299.

14. Piksa K, Górz A, Nowak-Chmura M, Siuda K: The patterns of seasonal activity of Ixodes vespertilionis (Acari: Ixodidae) on Rhinolophus hipposideros in nursery colonies. Ticks Tick Borne Dis 2014, 5:69-74.

15. Babos A, Janisch N: Ixodes chiropterorum sp. n., eine neue Zeckenart in Ungarn. Acta Vet Acad Sci Hung 1958, 8:389-399.

16. Beaucourni JC: On some palearctic Ixodoidea (Acarina) infesting microChiroptera. Ann Parasitol Hum Comp 1966, 41:495-502.

17. Rivers NM, Butlin RK, Altringham JD: Autumn swarming behaviour of Natterer's bats in the UK: population size, catchment area and dispersal. Biologic Conserv 2006, 127:215-226.

18. Casati S, Bernasconi MV, Gern L, Piffaretti JC: Assessment of intraspecific mtDNA variability of European Ixodes ricinus sensu stricto (Acari: Ixodidae). Infect Genet Evol 2008, 8:152-158.

19. Lu X, Lin XD, Wang JB, Qin XC, Tian JH, Guo WP, Fan FN, Shao R, Xu J, Zhang YZ: Molecular survey of hard ticks in endemic areas of tick-borne diseases in China. Ticks Tick Borne Dis 2013, 4:288-296.

doi:10.1186/1756-3305-7-202

Cite this article as: Hornok et al:: Bat ticks revisited: Ixodes ariadnae sp. nov. and allopatric genotypes of $I$. vespertilionis in caves of Hungary. Parasites \& Vectors 2014 7:202. 